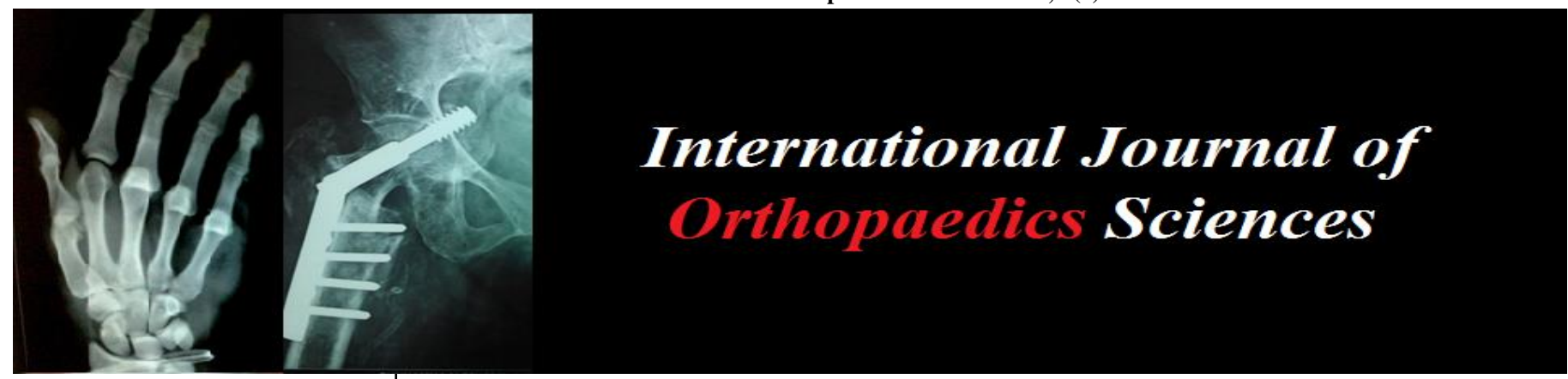

E-ISSN: 2395-1958

P-ISSN: 2706-6630

IJOS 2019; 5(4): 1040-1045

(C) 2019 IJOS

www.orthopaper.com

Received: 20-08-2019

Accepted: 24-09-2019

Dr. Sunil S

Senior Resident,

Chamarajanagar Institute of

Medical Science, Chamarajnagar,

Karnataka, India

Dr. Arjun K Unnam

Registrar, Department of

Arthroplasty, Hosmat Hospital,

Bangalore, Karnataka, India

Dr. TD Bhattacharyya

Professor, Department of

Orthopaedics, GMCH, Guwahati

Assam, India

\section{Comparitive analysis of interlocking intramedullary nail and locking compression plate in the treatment of diaphyseal humeral fractures}

\author{
Dr. Sunil S, Dr. Arjun K Unnam and Dr. TD Bhattacharyya
}

DOI: https://doi.org/10.22271/ortho.2019.v5.i4r.1818

Abstract

Introduction: Humerus fractures comprise $3-5 \%$ of all fractures in adults. These are best treated operatively to ensure optimal function. The main aim behind going for operation is for early mobilization in active adults. The usual modalities of operation used are intramedullary nailing and osteosynthesis with locking compression plate (LCP).

Materials and methods: A prospective study was carried out for 40 cases of humeral diaphyseal fractures out of which, 20 cases were treated with locking compression plate and 20 were treated with intra medullary nail. Serial follow up and assessment was done for radiological union and functional outcome.

Results: Average age 35.9 years. The commonest mode of injury was road traffic accident (RTA). Radial nerve palsy seen in only in $7.5 \%$ ( 3 cases) of the cases. Average time taken for union in IMN was 14.15 weeks and LCP was 15.15 weeks. Post-operative complications are less in LCP group than IMN group of patients.

Conclusion: Considering the functional outcome and rate of complications, we concluded that locking compression plating offers better result than interlocking nailing with respect to pain and function of the shoulder joint.

Keywords: Locking compression plate, intra medullary nail, road traffic accident

\section{Introduction}

Humeral shaft fractures are defined as fractures in which the major fracture line occurs distal to the insertion of the pectoralis major and proximal to the supracondylar ridge (excluding 5 $\mathrm{cm}$ from both the ends). It is estimated that these fractures comprise 3-5\% of all fractures in adults.

While the majority of humeral shaft fractures are appropriately treated non-operatively, there are humeral shaft fractures which are best treated operatively to ensure optimal function. The main aim behind going for operation is for early mobilization in active adults.

The indications for operative intervention for humeral shaft fractures include: segmental fractures; floating elbow injuries; open fractures; nonunions; and polytraumatic injuries in which partial upper extremity weight bearing would facilitate recovery of other injuries and allow early patient mobilization.

The usual modalities of operation used are intramedullary nailing and osteosynthesis with compression plate. Advocates of intramedullary fixation have highlighted various disadvantages of open reduction and internal fixation with compression plating which requires extensive open surgery with stripping of soft tissues from bone, a longer operative time and less secure fixation, especially in the elderly with osteoporotic bone and if crutch walking is required.

Intramedullary fixation is reported to involve a simpler technique with minimal exposure and shorter operative time with less blood loss, but impairment of shoulder function as a consequence of antegrade intramedullary fixation and residual fracture site distraction have been stated as disadvantages.
Dr. Sunil S

Senior Resident,

Chamarajanagar Institute of

Medical Science, Chamarajnagar,

Karnataka, India 
However locking compression plate chosen by us for comparision has some advantages like lower rate of elbow or shoulder morbidity and early upper extremity weight. Apart from the above, the locked screw has an added advantage of decreased screw loosening and hence thought to be useful in case of osteopenic bone.

The present study is designed to compare the outcome of patients treated with IM interlocking nail versus those treated with LCP in diaphyseal humeral fractures.

\section{Materials and Methods}

We conducted this prospective, comparative study in the department of orthopedics, Gauhati Medical College and Hospital, Guwahati from July 2011 to September 2012.

There were 40 human subjects who gave informed consent for the study. All the subjects were followed up for a minimum period of 5 months.

\subsection{Inclusion criteria}

1. Only fresh fractures (within 3 weeks of injury were taken up for the study)

2. All diaphyseal humeral fractures in patients aged 18$60 y$ rs of age.

3. Diaphyseal humeral fractures with neurological involvement

4. Comminuted and segmental diaphyseal humeral fractures.

5. Open fractures - Gustilo type I.

\subsection{Exclusion criteria}

1. Compound humeral fractures other than type I.

2. Medical contraindications to surgery

3. Diaphyseal humeral fractures with delayed union or nonunion.

4. Pathological fractures

\subsection{Surgical technique}

\subsubsection{Intramedullary interlocking nail fixation}

Under GA or regional anesthesia, with patient supine, his head is turned to the contralateral side to increase exposure of the shoulder. Under aseptic condition longitudinal skin incision is made from the most lateral point of the acromion and extended distally; the incision is centered over the tip of the grater tuberosity. Fascia over the deltoid is incised and the greater tuberosity is palpated. Point of insertion of the nail is medial to the tip of the greater tuberosity, Small curved awl is used to establish the entry portal just medial to the tip of the greater tuberosity. This is confirmed with the help of image intensifier. Curved awl is withdrawn and a $2.4 \mathrm{~mm}$ ball nosed reamer guide rod is inserted. The position of the guide wire in the center of the medullary canal is determined with the help of the image intensifier. Guide wire is advanced into the distal fragment until its tip is $1 \mathrm{~cm}$ to $2 \mathrm{~cm}$ proximal to the olecranon fossa. Entire length of the humerus is reamed over the $2.4 \mathrm{~mm}$ ball-nose reamer guide rod in $0.5 \mathrm{~mm}$ increments until the desired diameter is achieved. $1 \mathrm{~mm}$ larger than the selected nail diameter was reamed. Non cannulated humeral nail is inserted after the removal of the guide rod under roentgeographic control. Nail is advanced distally until $1-2 \mathrm{~cm}$ proximal to the olecranon fossa care is to be taken to avoid splintering of the distal humerus. Position of the nail in the distal fragment is confirmed by anteroposterior and lateral image intensification. Nail is locked proximally and distally with $4 \mathrm{~mm}$ locking screws.

\subsubsection{Technique of LCP Fixation}

The bone is exposed after dissection using either anterolateral or posterior approach to humerus and fracture site identified, cleaned \& approximated. Fracture fragments reduced and held with clamps, locking compression plate placed over bone after reduction and held with plate holding clamps and fixed with compression screws initially followed by locking screws. Wound closed in layers. Hemostasis secured. Dressing done. U slab applied.

2.3.3 Post-operative protocol: Intravenous antibiotics were given for 3days, wound dressing done on POD-2. Oral analgesics started from day 2. shoulder range of motion and elbow movements is begun within the 3rd or 4th postoperative day. X-rays were done at regular follow ups with stitch being removed after second week of surgery. Clinical and radiological parameters will be recorded. Patient follow up will be done on 1st, 3rd and 5th month postoperatively.

\section{Results}

40 patients aged between 18-60yrs with fracture shaft of humerus were selected according to the inclusion criteria and 20 patients were treated with Closed reduction \& internal fixation with interlocking nail amd 20 patients were treated with open reduction \& internal fixation with locking compression plate. The observations in our study were, In the LCP group there were 13 male patients and 7 female patients, in the ILN group there were 6 female and 14 male patients. A male predominance was noted in both the groups. The youngest patient was $22 \mathrm{yrs}$ old and the oldest patient was $60 \mathrm{yrs}$ old. The mean age was 35.9 yrs. The maximum number of cases were in the age group of 21-30 yrs. Of the 20 patients treated with Interlock humerus nail, the age ranged between $18-60 y r s$, the mean age was 34.55 yrs. Maximum number of cases were in the age group of 21-30 yrs. Of the 20 patients treated with Locking compression plate, the age ranged between 18-60yrs, the mean age was $37.35 y$ rs. Maximum number of cases were also in the age group of 21-30 yrs. The commonest mode of injury in our patients was road traffic accident (RTA), seen in $70 \%$ followed by injury due to fall in $30 \%$ of them. Majority of the fractures were located in the middle third, accounting for 22 cases and hence the most commonest site. Majority of the patients $(92.5 \%)$ did not have radial nerve injury. It was seen in only in $7.5 \%$ (3 cases) of the cases. No recovery was seen postoperatively and hence tendon transfer was required in 2 cases at 6 months follow up; one case lost follow up. For ILN the mean duration between trauma and surgery was 2.95 days; for the LCP, the mean duration was 3.95 days. The anterolateral approach was used in 14 patients who had fractures in the upper and middle third of the shaft and 6 patients were operated through the posterior approach who had fractures in the lower third of the shaft. The intra operative complications were higher in case of Interlocking Nail cases. The postoperative complications like shoulder impingement, shoulder stiffness and shoulder pain were more common with Interlocking Nail when compared to Locking Compression plate. Only one case of nonunion was seen throughout the study which was operated with Interlocking Nail without distal locking. The mean time taken for union in Interlocking Nail was 14.15 weeks and LCP was 15.15 weeks and 1 case had nonunion. The scoring system has maximum of 35 points with scores being depended upon pain, function, range of flexion of shoulder, flexion strength and patient satisfaction. 


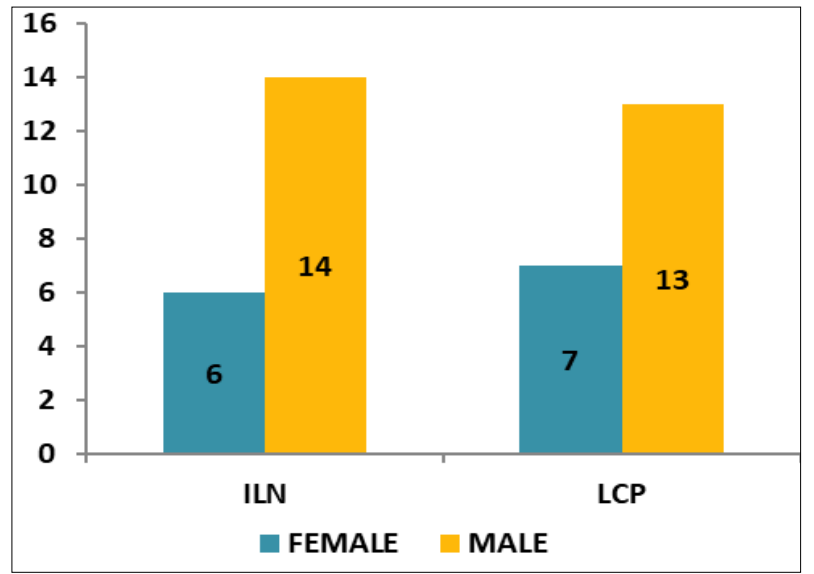

Fig 1: Sex distribution of patients $n=40$

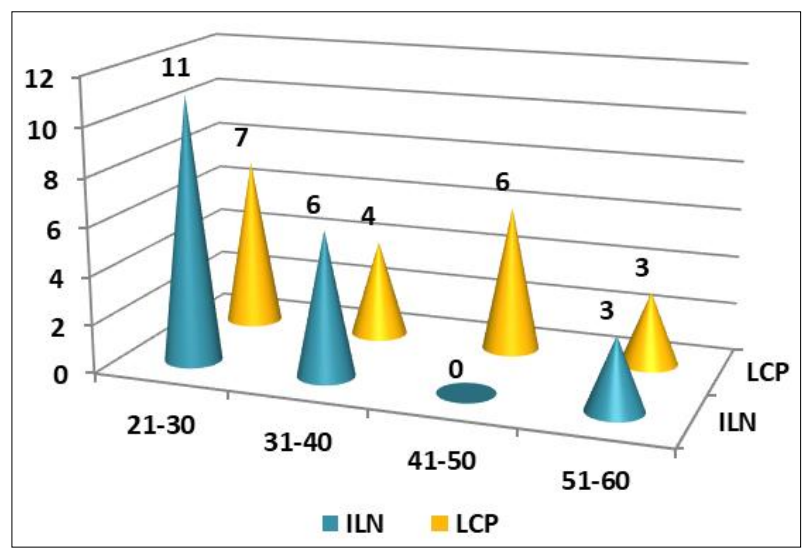

Fig 2: Age distribution of patients

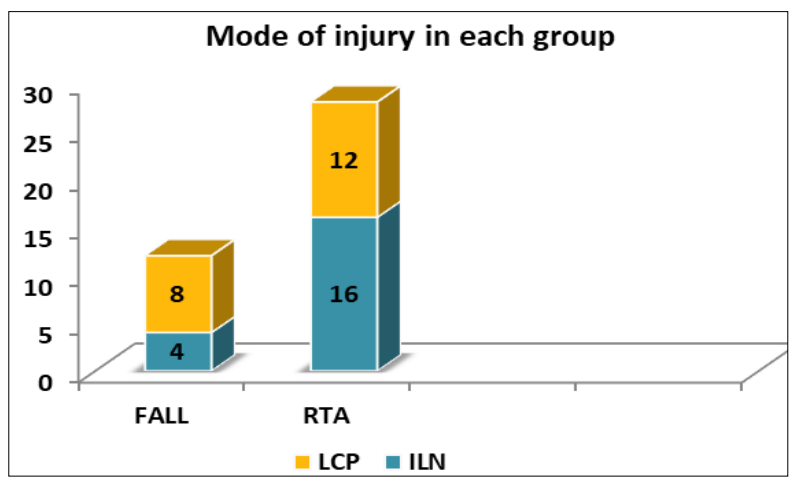

Fig 3: Mode of injury

Table 1: Side of injury

\begin{tabular}{|c|c|c|}
\hline Side & No of patients & Percentage \\
\hline Right & 25 & 62.5 \\
\hline Left & 15 & 37.5 \\
\hline Total & 40 & 100 \\
\hline
\end{tabular}

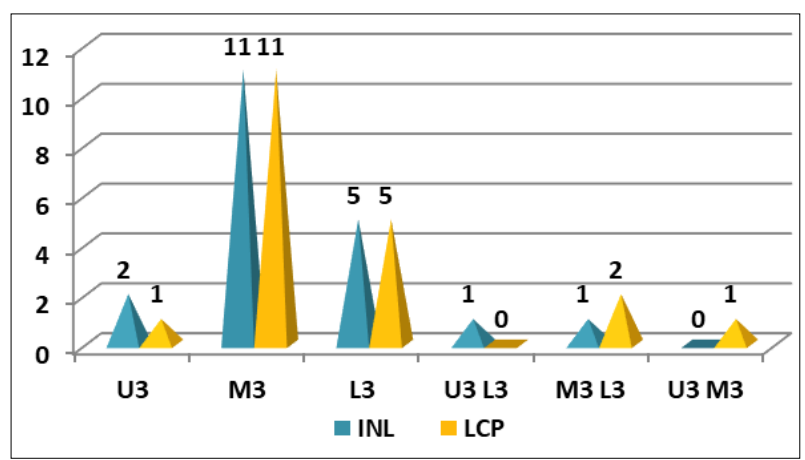

Fig 4: Levels of injury

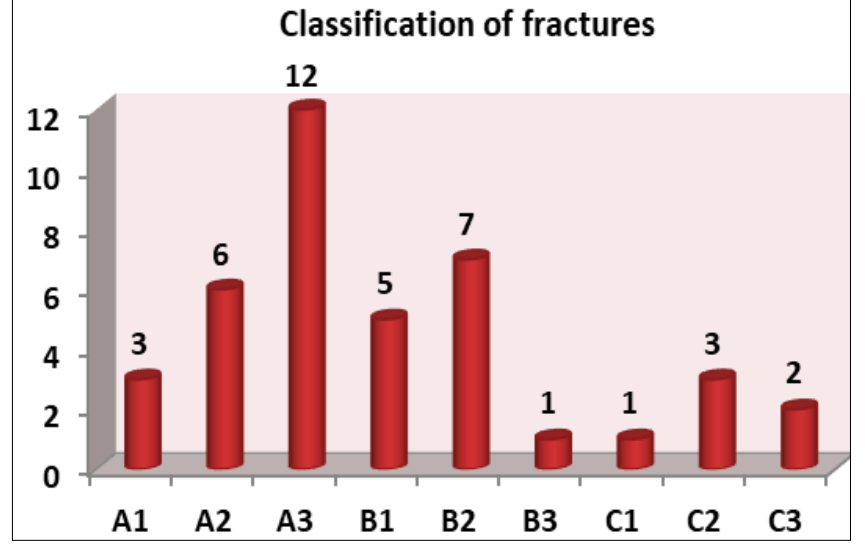

Fig 5: AO classification of fractures

Table 2: Radial nerve palsy

\begin{tabular}{|c|c|c|}
\hline Radial nerve palsy & Number of cases & Percentage \\
\hline Absent & 37 & 92.5 \\
\hline Present & 3 & 7.5 \\
\hline
\end{tabular}

Table 3: Intra operative complications

\begin{tabular}{|c|c|c|c|}
\hline \multirow{2}{*}{ Complications } & \multicolumn{2}{|c|}{ Group } & \multirow[b]{2}{*}{ Total } \\
\hline & ILN & LCP & \\
\hline Fracture at The Entry Point & $1(16.6 \%)$ & 0 & $1(12.5 \%)$ \\
\hline Commination at the Fracture Site & $1(16.6 \%)$ & 0 & $1(12.5 \%)$ \\
\hline Difficult Reduction & $1(16.6 \%)$ & $1(50 \%)$ & $2(25 \%)$ \\
\hline Problem in Locking & $3(50 \%)$ & 0 & $3(37.5 \%)$ \\
\hline Radial Nerve Entrapment & 0 & $1(50 \%)$ & $1(12.5 \%)$ \\
\hline Total & $6(100 \%)$ & $2(100 \%)$ & $8(100 \%)$ \\
\hline
\end{tabular}

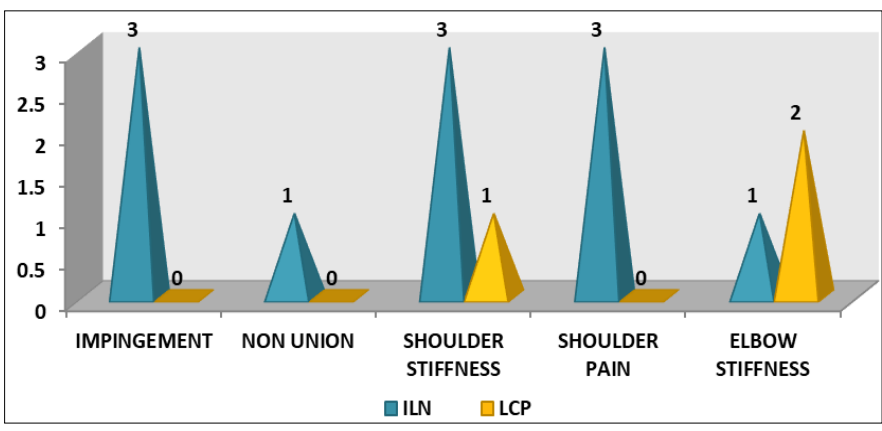

Fig 6: Postoperative complications $\mathrm{p}=0.098$

Table 4: Time taken for union

\begin{tabular}{|c|c|c|c|}
\hline \multirow{3}{*}{ Union } & Groups & Cases & Mean \\
\cline { 2 - 4 } IN Weeks & ILN & 19 & 14.15 weeks \\
\cline { 2 - 4 } & LCP & 20 & 15.15 weeks \\
\hline
\end{tabular}

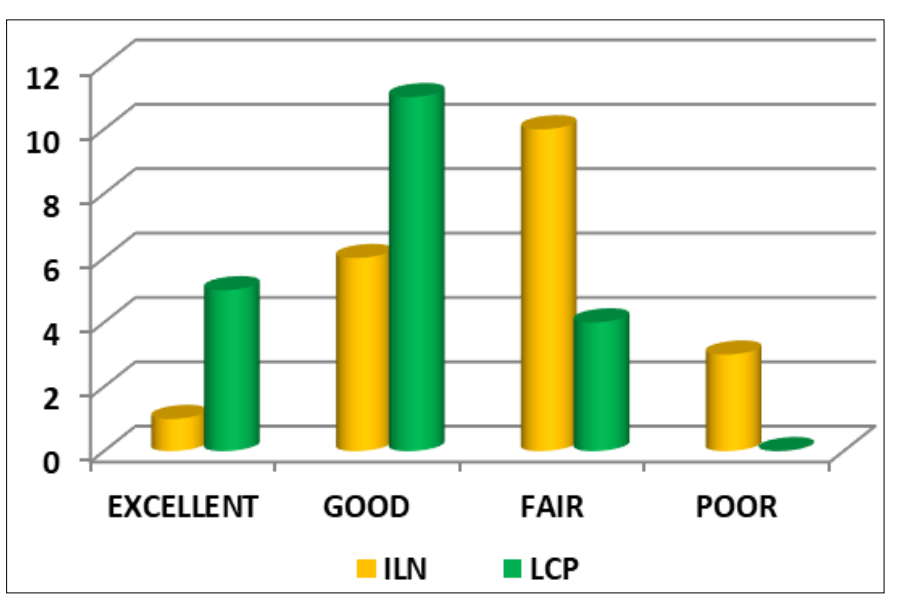

Fig 7: Functional results $\mathrm{P}=0.021$ 


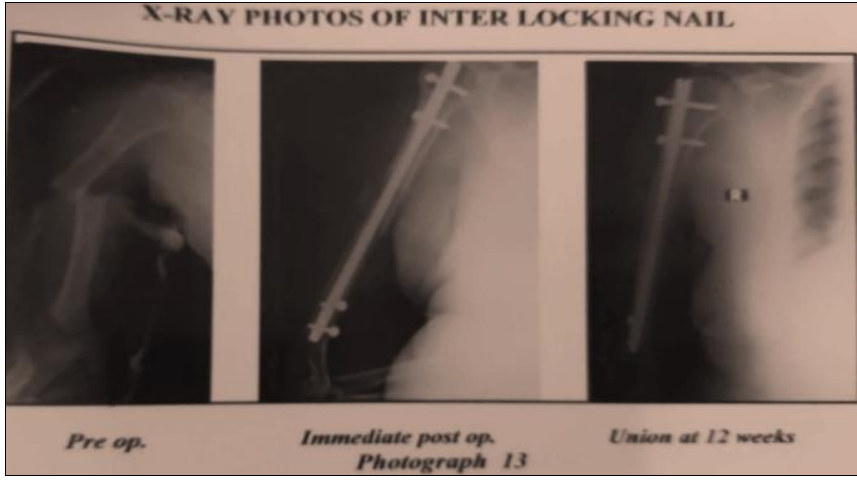

Fig 8: X-rays of inter locking nail

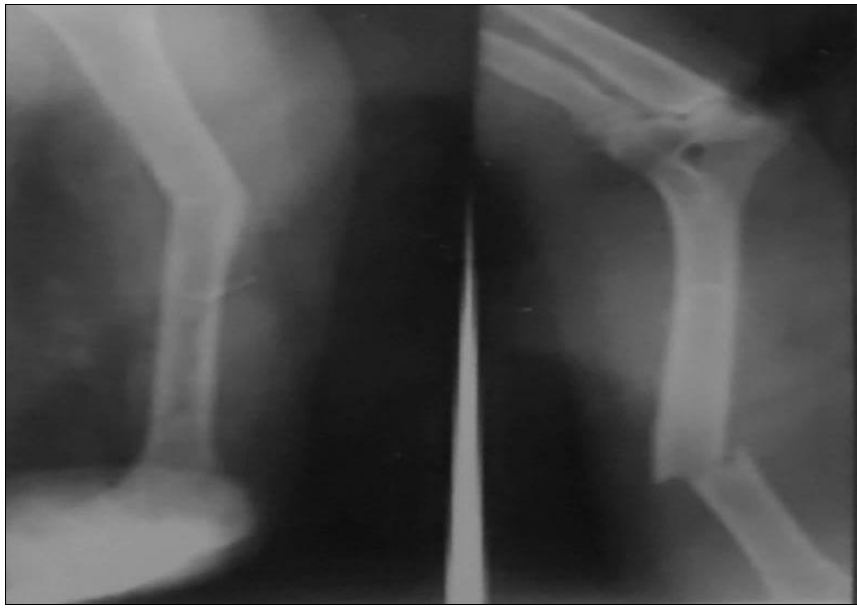

Fig 9: Pre op x-ray of humerus fracture

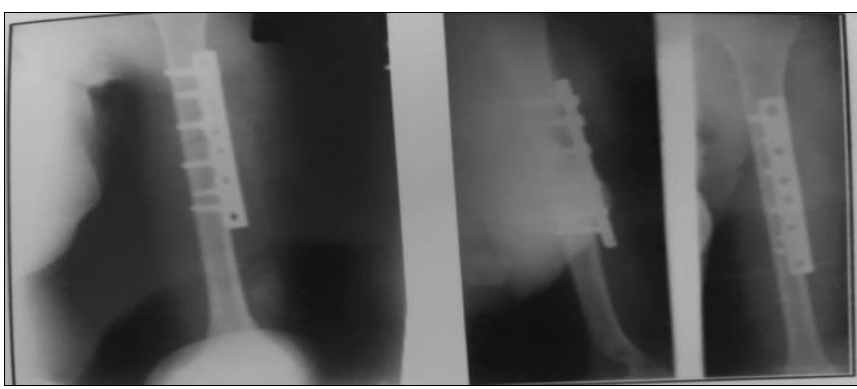

Fig 10: Immediate post op and 14 weeks follow up x-rays

\section{Discussion}

Most surgeons agree that intramedullary nailing is the best internal fixation for femoral and tibial shaft fractures, but there is no agreement about the ideal procedure for fractures of the humeral shaft. Plate osteosynthesis requires extensive soft tissue dissection with the risk of radial nerve damage.

The indications for open reduction and internal fixation of acute fractures of the humeral shaft have been described as: fractures in patients with multiple injuries, open fractures, fractures associated with vascular or neural injuries or with lesions of the shoulder, elbow or forearm in the same limb; bilateral upper extremity injuries, fractures for which closed methods of treatment have failed and pathological fractures. In several reported series, the presence of associated multiple injuries was the most frequent indication for internal fixation of the humeral shaft. In our study failed closed reduction and associated injuries were the most common indications.

In our study, the age of the patients ranged from 22-60yrs and the average age being 35.9 years, similar to the studies of $A B$
Putti ${ }^{[6]}$ et al. and Crates and Whittle et al. ${ }^{[2]}$. The present study and the reference studies show that fracture shaft humerus is more common in the adult population rather than the elderly population. Male gender was predominant in our study which was comparable with the other studies. The right side was seen to be predominantly involved in our study which is similar to the studies of Lin and $\mathrm{Hou}^{4}$ et al and Ferreiraneto et al. ${ }^{[7]}$. The commonest mode of injury was road traffic accidents which is compared to the other studies. In our study it was observed that fracture in the middle one third of the shaft of humerus was the commonest location of the fracture and comparable to the other studies.

Table 5: Comparison of the age incidence in our study with other studies

\begin{tabular}{|c|c|c|}
\hline Study & $\begin{array}{c}\text { Age range } \\
\text { (Years) }\end{array}$ & $\begin{array}{c}\text { Average age } \\
\text { (Years) }\end{array}$ \\
\hline${\text { Ingman\& Waters } \text { et al. }{ }^{[1]}}^{16-90 y r s}$ & 53 \\
\hline Crates and Whittle et al. ${ }^{[2]}$ & $13-75 \mathrm{yrs}$ & 32 \\
\hline Rommens et al. ${ }^{[3]}$ & $16-19 \mathrm{yrs}$ & 55.1 \\
\hline Lin and Hou et al. ${ }^{[4]}$ & $20-82 \mathrm{yrs}$ & 42.6 \\
\hline McCormack RG et al. ${ }^{[5]}$ & $19-82 \mathrm{yrs}$ & 40 \\
\hline AB Putti et al. ${ }^{6]}$ & $23-84 \mathrm{yrs}$ & 36 \\
\hline Present Study & $22-60 \mathrm{yrs}$ & 35.9 \\
\hline \multicolumn{2}{|r}{}
\end{tabular}

Table 6: Gender comparison with other studies

\begin{tabular}{|c|c|c|}
\hline Study & No of males & No of females \\
\hline Ingman\& Waters et al. ${ }^{[1]}$ & 21 & 20 \\
\hline Crates and Whittle et al. ${ }^{[2]}$ & 43 & 2 \\
\hline Rommens et al. ${ }^{[3]}$ & 100 & 90 \\
\hline Lin and Hou et al. ${ }^{[4]}$ & 28 & 19 \\
\hline AB Putti et al. ${ }^{[6]}$ & 32 & 2 \\
\hline Present Study & 27 & 13 \\
\hline
\end{tabular}

Table 7: Side involved comparison with other studies

\begin{tabular}{|c|c|c|}
\hline \multirow{2}{*}{ Study } & \multicolumn{2}{|c|}{ Side involved } \\
\cline { 2 - 3 } & Right & Left \\
\hline Lin and Hou et al. ${ }^{[4]}$ & 18 & 22 \\
\hline Ferreiraneto et al. ${ }^{[7]}$ & 15 & 10 \\
\hline Present Study & 25 & 15 \\
\hline
\end{tabular}

Table 8: Mode of injury

\begin{tabular}{|c|c|c|}
\hline Study & \multicolumn{2}{|c|}{ Common mode of injury with percentage } \\
\hline Ferreiraneto et al. ${ }^{[7]}$ & RTA & $48 \%$ \\
\hline Singisetti et al. ${ }^{[8]}$ & RTA & $85 \%$ \\
\hline Changulani et al. ${ }^{[9]}$ & RTA & $70.2 \%$ \\
\hline AB Putti et al. ${ }^{[6]}$ & RTA & $82.35 \%$ \\
\hline Present Study & RTA & $70 \%$ \\
\hline
\end{tabular}

Table 9: Location of fracture Percentage

\begin{tabular}{|c|c|c|}
\hline Study & Location of fracture & Percentage \\
\hline Rommen et al. ${ }^{[3]}$ & Middle one third & $60.5 \%$ \\
\hline Lin et al. ${ }^{[10]}$ & Middle one third & $54.16 \%$ \\
\hline Present Study & Middle one third & $55 \%$ \\
\hline
\end{tabular}

In our study 39 of 40 fractures united. The one that went for nonunion was from the Interlocking nail group. The mean time taken for union in the Interlocking nail group was 14.15 weeks and for that with locking compression plate it was 15.15 weeks. The following table shows the comparison for the time taken for union in our study with the other study groups 
Table 10: Union time comparison

\begin{tabular}{|c|c|c|}
\hline Study & Operation & Union time (In weeks) \\
\hline Lin et al. ${ }^{[10]}$ & ILN & 8.6 \\
\hline Lin and Hout et al. ${ }^{[4]}$ & ILN & 7.8 \\
\hline Ferreiranto et al. ${ }^{[7]}$ & ILN & 9.6 \\
\hline Changulani et al. ${ }^{[9]}$ & ILN & 8.9 \\
\hline Walia et al. ${ }^{[11]}$ & LCP & 13.3 \\
\hline \multirow{2}{*}{ Present study } & ILN & 14.15 \\
\cline { 2 - 3 } & LCP & 15.15 \\
\hline
\end{tabular}

The functional results were evaluated using UCLA evaluation criteria and Ellmans criteria. We observed: 5\% excellent results in ILN group compared to $25 \%$ in the LCP group; $30 \%$ good results in ILN group compared to $55 \%$ in the LCP group; $50 \%$ fair results in ILN group compared to $20 \%$ in the LCP group and $15 \%$ poor results in ILN group but no cases with poor results in the LCP group. The significant $\mathrm{p}$ value ( $p=0.021)$ shows better functional result in LCP group over ILN group. Lin and Hou et al. ${ }^{[4]}$ got excellent results in ILN group. Other studies showed results on par with our study

Table 11: Functional outcome

\begin{tabular}{|c|c|c|}
\hline Study & Operation & Results \\
\hline \multirow{4}{*}{$\begin{array}{l}\text { Ferreiraneto et al. }{ }^{[7]} \\
2007\end{array}$} & \multirow{4}{*}{ LN } & Excellent-27.3\% \\
\hline & & Good- $63.6 \%$ \\
\hline & & Fair- $9.1 \%$ \\
\hline & & Poor -05 \\
\hline \multirow{4}{*}{$\begin{array}{c}\text { Kiran Singisetti et al. }{ }^{[8]} \\
2008\end{array}$} & \multirow{4}{*}{ ILN } & Excellent- $20 \%$ \\
\hline & & Good- $45 \%$ \\
\hline & & Fair- $25 \%$ \\
\hline & & Poor $-10 \%$ \\
\hline \multirow{4}{*}{$\begin{array}{c}\text { Raghavendra S et al. }{ }^{[12]} \\
2007\end{array}$} & \multirow{4}{*}{ ILN } & Excellent $-6.25 \%$ \\
\hline & & Good- $18.75 \%$ \\
\hline & & Fair- $56.25 \%$ \\
\hline & & Poor- $18.75 \%$ \\
\hline Lin \&Hou et al. ${ }^{[4]}$ & ILN & Excellent or satisfactory- $92.5 \%$ \\
\hline \multirow{2}{*}{ Walia JPS et al. ${ }^{[11]} 2009$} & \multirow{2}{*}{ LCP } & Satisfactory- $80 \%$ \\
\hline & & Unsatisfactory- $20 \%$ \\
\hline \multirow{8}{*}{ Present study } & \multirow{4}{*}{ ILN } & Excellent $-25 \%$ \\
\hline & & Good-30\% \\
\hline & & Fair-50\% \\
\hline & & Poor- $15 \%$ \\
\hline & \multirow{4}{*}{ LCP } & Excellent $-25 \%$ \\
\hline & & Good- $55 \%$ \\
\hline & & Fair-20\% \\
\hline & & Poor- $0 \%$ \\
\hline
\end{tabular}

No surgical procedure is free from complication. Some complications were encountered in the present study. Shoulder pain due to impingement was one of the main complications noted in the Interlock nail group which was not seen in Locking plate compression group. Shoulder range of motion may be limited by bursal and capsular adhesions. It often results if there is inadequate rehabilitation after an operative procedure. In our study, we encountered 3 cases of shoulder stiffness in ILN group and 1 case in LCP group. In our study we encountered only 1 case of non-union in the Interlocking nail group in which distal locking was not done due to technical reasons. All cases of Locking compression plate had union without fail. This is a complication associated with Interlock Nail due to faulty entry point. Putti $\mathrm{AB}^{6}$ et al showed 1 case of fracture at the entry point. In our study, we also had 1 case of fracture at the greater tuberosity during nail insertion. In the present study we encountered 3 cases where distal locking screw could not be inserted in Interlock Nail cases. 2 out of these got united, but 1 case had nonunion inspite of the "U" slab being kept for a considerable amount of time. The study of Putti AB et al also had 1 case where locking was a problem. In the present study we did not encounter other common complications like infections and injury to nerves and vessels intra operatively.

Table12: nonunion cases comparison with other studies

\begin{tabular}{|c|c|c|c|}
\hline Study & Operation & $\begin{array}{c}\text { Total No of } \\
\text { CASES }\end{array}$ & Non union \\
\hline Crates \& Whittle et al. $^{[2]}$ & ILN & 71 & 4 \\
\hline Changulani et al. ${ }^{\left[{ }^{[5]}\right.}$ & ILN & 21 & 3 \\
\hline McCormack et al. ${ }^{[5]}$ & ILN & 21 & 2 \\
\hline AB Putti et al. ${ }^{[6]}$ & ILN & 16 & 0 \\
\hline Walia JPS et al. ${ }^{[11]}$ & LCP & 10 & 0 \\
\hline $\begin{array}{c}\text { Present } \\
\text { Study }\end{array}$ & ILN & 20 & 1 \\
\cline { 2 - 4 } & LCP & 20 & 0 \\
\hline
\end{tabular}

\section{Conclusion}

Though there are specific indications for intramedullary nailing of humeral fractures like pathological fractures and osteoporotic fractures, considering the functional outcome and rate of complications, we concluded that locking compression plating offers better result than interlocking nailing with respect to pain and function of the shoulder joint. Hence in cases where both nailing and plating can be done, our study shows that plate osteosynthesis should be the method of choice for fixation of humaeral shatft fractures.

\section{References}

1. Ingman AM, Waters DA. Locked intramedullary nailing of humeral shaft fractures: Implant design, Surgical technique and Clinical results. J Bone Joint Surg. 1994; 76B:23-29.

2. Crates J, Whittle AP. Antegrade interlocking nailing of acute humeral shaft fractures. Clin Orthop Relat Res. 1998; 350:40-50. [PubMed] [Google Scholar]

3. Rommens PM, Verbruggen J, Broos PL. Retrograde locked nailing of humeral shaft fractures. J Bone Joint Surg Br. 1995; 77(1):84-89. [PubMed] [Google Scholar]

4. Lin J, Hou SM, Inoue N, Chao EY, Hang YS. Anatomic considerations of locked humeral nailing. Clin Orthop Relat Res. 1999; 368:247-54. [PubMed] [Google Scholar]

5. McCormack RG, Brien D, Buckley RE et al. Fixation of fractures of the shaft of the humerus by dynamic compression plate or intramedullary nail. A prospective, randomised trial. J Bone Joint Surg. 2000; 82-B:336-339

6. Putti AB, Uppin RB, Putti BB. Locked intramedullary nailing versus dynamic compression plating for humeral shaft fractures. J Orthop Surg (Hong Kong). 2009; 17:139-141.

7. Ferreira Neto AA, Benegas E, Gracitelli ME et al. Shoulder function after surgical treatment of displaced fractures of the humeral shaft: a randomized trial comparing antegrade intramedullary nailing with minimally invasive plate osteosynthesis. J Shoulder Elbow Surg. 2014; 23:767-74. [PubMed] [Google Scholar]

8. Singisetti K, Ambedkar M. Nailing versus plating in humerus shaft fractures: a prospective comparative study. Int Orthop. 2010; 34:571-576.

9. Changulani M, Jain UK, Keswani T. Comparison of the use of the humerus intramedullary nail and dynamic compression plate for the management of diaphyseal fractures of the humerus. A randomised controlled 
study. Int. Orthop. 2007; 31:391-395.

10. Lin J, Shen PW, Sheng-Mon H. Complications of locked nailing in humeral shaft fractures. J Trauma. 2002; 54(4):943-949.

11. JPS Walia MS, Avinashgupta MS, Girishsahani, Gagandeepgupta, Sonamkaurwalia. Role of locking compression plate in long bone fractures in adults. $\mathrm{Pb}$ journal of orthopaedics. 2009; 11(1):41-43

12. Raghavendra S, Bhalodiya HP. Internal fixation of fractures of the shaft of the humerus by dynamic compression plate or intramedullary nail: A prospective study. Indian J Orthop. 2007; 41(3):214-218. Doi: 10.4103/0019-5413.33685. 